\title{
Studies on Erosion Behavior of Plasma Sprayed Coatings of Glass Microspheres Premixed with $\mathrm{Al}_{2} \mathrm{O}_{3}$ Particles
}

\author{
Gaurav Gupta and Alok Satapathy \\ Department of Mechanical Engineering, National Institute of Technology, Rourkela, Odisha 769008, India \\ Correspondence should be addressed to Gaurav Gupta; gauravgupta198606@gmail.com
}

Received 20 November 2013; Revised 17 February 2014; Accepted 17 February 2014; Published 31 March 2014

Academic Editor: Huseyin Çimenoğlu

Copyright (C) 2014 G. Gupta and A. Satapathy. This is an open access article distributed under the Creative Commons Attribution License, which permits unrestricted use, distribution, and reproduction in any medium, provided the original work is properly cited.

Solid particle erosion (SPE) tests are carried out to evaluate the performance of plasma sprayed coatings of borosilicate glass microspheres (BGM) premixed with $\mathrm{Al}_{2} \mathrm{O}_{3}$ particles on metallic substrates. For this purpose, an Air Jet Erosion test rig confirming to ASTM G 76 test standards is used. Relative influence of different operating parameters on erosion rate is assessed by statistical analysis of the experimental findings that are based on Taguchi's $\mathrm{L}_{16}$ orthogonal array. This analysis helps to identify the most significant factor affecting the erosion wear rate of the coating. The study reveals that the impact velocity, impingement angle, erodent size, and $\mathrm{Al}_{2} \mathrm{O}_{3}$ content in the feed stock, in the declining sequence, are the significant factors influencing the wear rate of these coatings. An Artificial Neural Network (ANN) approach is then implemented taking into account training and test procedure to predict the triboperformance of these coatings under wear conditions beyond the experimental range. Further, the microstructural features of the eroded samples are studied from SEM images to identify possible wear mechanisms.

\section{Introduction}

Plasma spray coating is a typical thermal spray process that combines particle melting, quenching, and consolidation in a single operation. It utilizes the exotic properties of the plasma medium to different materials and it has the advantage of being able to process various low-grade-ore minerals to obtain value added products and also to deposit ceramics, metals, and so forth generating near homogenous coatings with the desired microstructure [1]. This coating technology has been widely adopted by many industries due to its flexibility, superior quality, and high deposition rate. Plasma sprayed coatings have been widely applied in industrial components in several industries $[2,3]$ in a wide range of functionalities and engineering designs such as in free standing or near net shape parts $[4,5]$, environmental clean alternative [6], protection of nuclear equipment [7], and medical purposes $[8,9]$. One of the most important and widely used applications of plasma spray coatings is their use as wear resistant coatings [10-14].

Plasma sprayed coatings are being applied on engineering as well as structural components, where erosion occurs frequently. Due to severe dusty industrial environments, the study of solid particle erosive analysis of these coatings becomes highly relevant [15]. Erosion is one of the most important wear phenomena. It is caused by the impact of dispersed particles in a gas or liquid flow on the surface of materials. This in turn reduces the life of the mechanical components used in many industrial applications [16]. There are different types of erosion wear depending on the types of erodent and the methods of impact like slurry erosion, solid particle erosion, liquid impact erosion, and cavitation erosion [16]. Solid particle erosion is the progressive loss of original material from a solid surface due to mechanical interaction between that surface and impinging solid particles. Solid particle erosion (SPE) is a wear process where particles strike against a surface and promote material loss. During flight, a particle carries momentum and kinetic energy, which can be dissipated during impact due to its interaction with a target surface [17]. In some cases, SPE is a useful phenomenon, such as in sand blasting and high speed abrasive water jet cutting; but it is a serious problem in many engineering systems, including steam and jet turbines, pipelines and valves carrying particulate matter, and fluidized bed combustion 
(FBC) systems [18-21]. To reduce wear, all process parameters are needed to be understood, so as to undertake appropriate steps in the design of substrates and coating materials [22]. As the number of such process variables is too large, statistical techniques could be employed for identification of significant process parameters for optimization. In recent years, the Taguchi experimental design technique has become an excellent tool for improving performance output and optimizing the process [23]. Hence, in this investigation, the Taguchi experimental design has been adopted to find out the relative effects of impingement angle, impact velocity, erodent size, erodent temperature, and alumina content in the feed stock on the erosion wear rate of coatings of borosilicate glass microspheres (BGM) premixed with alumina powder in different proportions.

Borosilicate glass has excellent thermal properties with its low coefficient of expansion and high softening point; it also offers a high level of resistance to attack from water, acids, salt solutions, organic solvents, and halogens. Borosilicate glass is mainly composed of silica (70-80\%), boric oxide $\mathrm{B}_{2} \mathrm{O}_{3}(7-13 \%)$, and smaller amounts of the alkalis such as 4$8 \%$ of $\mathrm{Na}_{2} \mathrm{O}$ and $\mathrm{K}_{2} \mathrm{O}$ and $2-7 \%$ aluminum oxide $\left(\mathrm{Al}_{2} \mathrm{O}_{3}\right)$ [24]. Boron gives greater resistance to thermal changes and chemical corrosion. It is suitable for industrial chemical process plants, in laboratories, in the pharmaceutical industry, in bulbs for high powered lamps, and so forth. Borosilicate glass is also used at home for cooking plates and other heat resistant products. It is used for domestic kitchens and chemistry laboratories; this is because it has greater resistance to thermal shock and allows for greater accuracy in laboratory measurements in heating and cooling experiments. Glass microspheres are potential coating materials and can be preferred over irregular ones due to low surface area to volume ratio, high density, free flowing ability and close sizing, and so forth [25].

In the present work artificial neural network (ANN) approach has also been applied for predicting erosion wear rate of $\mathrm{BGM}-\mathrm{Al}_{2} \mathrm{O}_{3}$ coatings. ANN is a powerful mathematical tool and has been successfully used in many fields in the past [26-28]. Inspired by the biological nervous system, the neural networks are composed of elements called neurons operating in parallel. The transfer function between the elements, which is often nonlinear, plays an important role in the prediction quality and a definite function of this ANN can be trained through adjusting the values of weights.

\section{Experimental Details}

The most important step in plasma spray coating technique is the surface preparation of the substrate in order to increase the mechanical anchoring between the substrate and the coating. The substrates are therefore subjected to grit blasting to have the desired surface roughness. For this, high pressure compressed air carrying alumina particles is used. Surface roughness of about $7-8 \mu \mathrm{m}$ is obtained in order to get better mechanical anchoring [29]. The coating process is carried out at the Institute of Minerals and Materials Technology, Bhubaneswar, India, using an $80 \mathrm{~kW}$ atmospheric plasma spray system working in the nontransferred arc mode

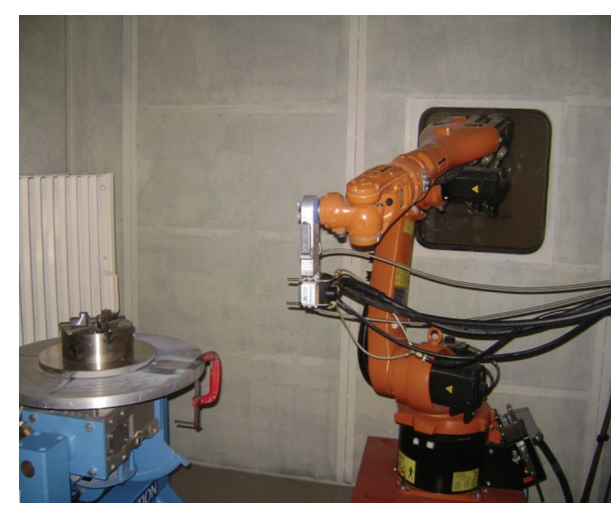

FIGURE 1: $80 \mathrm{~kW}$ atmospheric plasma spray system.

(Figure 1). This setup mainly consists of a spray torch, sixaxis robot, powder feeder, power supply, mass flow controller, a robot controller, control console, substrate holder, plasma gas supply, cooling water, and spray booth. Grit blasted aluminium and mild steel specimens of size $120 \times 60 \times$ $4 \mathrm{~mm}$ are fixed on the substrate holder and deposition of glass microspheres premixed with spray grade aluminium oxide particles in different proportions (10, 20 and $30 \mathrm{wt} \%)$ is carried out at a constant powder feed rate of $25 \mathrm{~g} \mathrm{~min}^{-1}$. Coating deposition is made at five different torch input power levels $(8,12,16,20$, and $24 \mathrm{~kW})$ by suitably varying the plasma arc current and arc voltage. Primary gas flow is varying in between 25 and $35 \mathrm{NL} / \mathrm{min}$ and secondary gas flow is varying in between 2 and $6 \mathrm{NL} / \mathrm{min}$. Torch to base distance is kept fixed at $100 \mathrm{~mm}$.

The set up for the solid particle erosion wear test used in this study is capable of creating reproducible erosive situations for assessing erosion wear resistance of the prepared samples. The schematic diagram of the erosion test rig is given in Figure 2. Mainly the test rig consists of an air compressor, an air drying unit, a conveyor belt-type particle feeder, and an air particle mixing and accelerating chamber. In the present study, dry silica sand of different particle sizes $(50 \mu \mathrm{m}, 100 \mu \mathrm{m}, 150 \mu \mathrm{m}$, and $200 \mu \mathrm{m})$ are used as the erodent. The dried and compressed air is mixed with the erodent which is fed constantly by a conveyor belt feeder into the mixing chamber and then is accelerated by passing the mixture through a convergent brass nozzle of $3 \mathrm{~mm}$ internal diameter. The erodent particles impact the specimen which can be held at different angles with respect to the direction of erodent flow using a swivel and an adjustable clip. The velocity of the eroding particles is determined using the standard double disc method [30]. The apparatus is equipped with a heater which can regulate and maintain the erodent temperature at any predetermined fixed value during an erosion trial. The samples are cleaned in acetone, dried, and weighed before and after the erosion trials using a precision electronic balance to an accuracy of $\pm 0.1 \mathrm{mg}$. The weight loss is recorded for subsequent calculation of erosion rate. The process is repeated till the erosion rate attains a constant value called steady state erosion rate. 


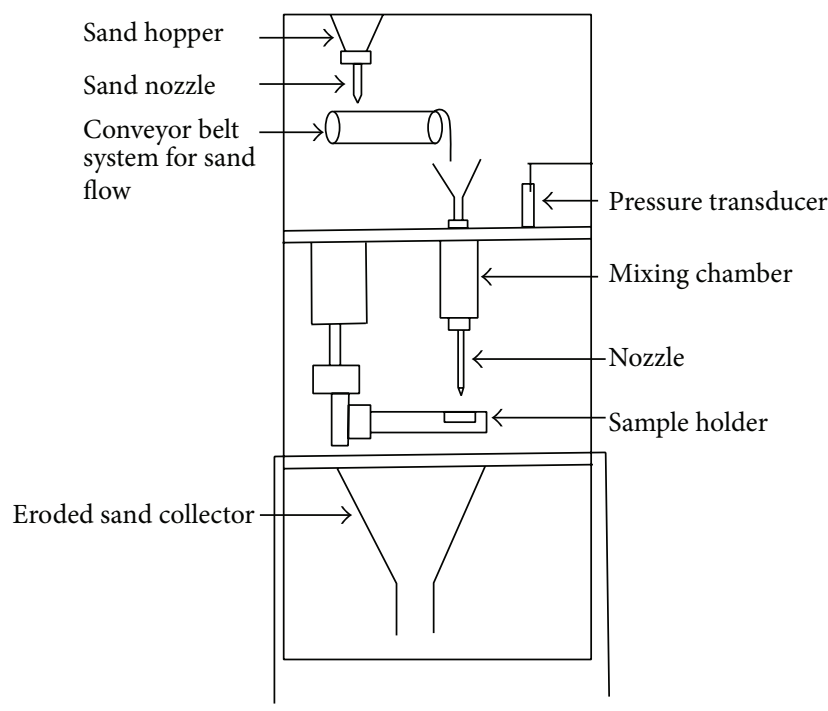

FIGURE 2: Solid particle erosion test setup.

TABLE 1: Setting of parameters.

\begin{tabular}{lccc}
\hline Control factors & Symbols & Fixed parameters & \\
\hline $\begin{array}{l}\text { Impact velocity } \\
\text { Impingement } \\
\text { angle }\end{array}$ & Factor $A$ & Erodent & Silica sand \\
$\begin{array}{l}\text { Erodent size } \\
\text { Erodent } \\
\text { temperature }\end{array}$ & Factor $C$ & Stand-off distance & $100 \mathrm{~mm}$ \\
$\begin{array}{l}\text { Alumina } \\
\text { content }\end{array}$ & Factor $D$ & Nozzle diameter & $3 \mathrm{~mm}$ \\
\hline
\end{tabular}

TABLE 2: Levels of the variables used in the experiment.

\begin{tabular}{lccccc}
\hline \multirow{2}{*}{ Control factor } & \multicolumn{5}{c}{ Level } \\
& I & II & III & IV & Unit \\
\hline Impact velocity & 32 & 40 & 48 & 56 & $\mathrm{~m} \mathrm{~s}^{-1}$ \\
Impingement angle & 30 & 45 & 60 & 90 & Degree \\
Erodent size & 50 & 100 & 150 & 200 & $\mu \mathrm{m}$ \\
Erodent temperature & 30 & 60 & 90 & 120 & ${ }^{\circ} \mathrm{C}$ \\
Alumina content & 0 & 10 & 20 & 30 & $\mathrm{wt} \%$ \\
\hline
\end{tabular}

Specimens of size $10 \times 13 \mathrm{~mm}$ are sliced from the uneroded and eroded samples for microscopic observation. The top surfaces of the specimens are observed under scanning electron microscope JEOL JSM-6480LV, by using the secondary electron imaging. To enhance the electrical conductivity of the samples, a thin film of platinum is vacuumevaporated onto them before the photomicrographs are taken.

Functional coatings have to fulfill various requirements when employed in tribological applications. The wear rate is one of the requirements because it is directly related to the service life period of the coating. In order to achieve a certain degree of erosion wear resistance accurately and repeatedly, the influence parameters of the process have to be controlled accordingly. Taguchi's experimental design can thus be used as a tool in such a case to make parametric appraisal of such processes in a real-time parameter space.

Statistical methods are commonly used to improve the quality of a product or process. Such methods enable the user to define and study the effect of every single condition possible in an experiment where numerous factors are involved. Solid particle erosion is such a process in which a number of control factors collectively determine the performance output, that is, the erosion rate. In this context, Taguchi experimental design happens to be a powerful analysis tool for modeling and analyzing the influence of control factors on performance output. Taguchi's method uses a statistical measure of performance called signal-to-noise ratio $(S / N)$, which is the logarithmic function of desired output to serve as objective functions for optimization. The ratio depends on the qualitative characteristics/attributes of the product/process/experimental variables to be optimized. The three categories of $S / N$ ratios that are used are smallerthe-better (SB), higher-the-better (HB), and nominal-thebest (NB). The $S / N$ ratio for minimum erosion rate (ER) falling under smaller-the-better norm can be calculated as

logarithmic transformation of the loss function as shown below:

$$
\frac{S}{N}=-10 \log \frac{1}{n}\left(\sum y^{2}\right) .
$$

Here, " $n$ " is the number of observations and " $y$ " is the observed data.

The erosion wear tests on the coatings are carried out under different operating conditions listed in Table 1. Different control factors and their selected levels are given in Table 2.

The plan of the experiments is as follows: the first column is assigned to impact velocity $(A)$, the second column to impingement angle $(B)$, the third column to erodent size $(C)$, the fourth column to erodent temperature $(D)$, and the fifth column to alumina content $(E)$, respectively, to estimate erosion rate. The impacts of these five parameters are studied using an $\mathrm{L}_{16}$ orthogonal array (Table 3 ). The experimental observations, that is, the wear rates are further transformed into corresponding signal-to-noise $(S / N)$ ratios.

In conventional full factorial experimental design, it would require $4^{5}=1024$ runs to study five factors each at four levels, whereas Taguchi's factorial experiment approach reduces it to only 16 runs offering a great advantage in terms of experimental time and cost.

An artificial neural network is a technique that involves database training to predict input-output evolutions. Basically this technology is suitable for some complex, nonlinear, and multidimensional problems because it is able to imitate the learning capability of human beings. This means that the network can learn directly from the examples without any prior formulae about the nature of the problem and generalize by itself some knowledge, which could be applied for new cases. A neural network is a system composed of many crosslinked simple processing units called neurons. The network 
TABLE 3: Orthogonal array for $\mathrm{L}_{16}\left(4^{5}\right)$ Taguchi design.

\begin{tabular}{llllll}
\hline Experiment number & $A$ & $B$ & $C$ & $D$ & $E$ \\
\hline 1 & 1 & 1 & 1 & 1 & 1 \\
2 & 1 & 2 & 2 & 2 & 2 \\
3 & 1 & 3 & 3 & 3 & 3 \\
4 & 1 & 4 & 4 & 4 & 4 \\
5 & 2 & 1 & 2 & 3 & 4 \\
6 & 2 & 2 & 1 & 4 & 3 \\
7 & 2 & 3 & 4 & 1 & 2 \\
8 & 2 & 4 & 3 & 2 & 1 \\
9 & 3 & 1 & 3 & 4 & 2 \\
10 & 3 & 2 & 4 & 3 & 1 \\
11 & 3 & 3 & 1 & 2 & 4 \\
12 & 3 & 4 & 2 & 1 & 3 \\
13 & 4 & 1 & 4 & 2 & 3 \\
14 & 4 & 2 & 3 & 1 & 4 \\
15 & 4 & 3 & 2 & 4 & 1 \\
16 & 4 & 4 & 1 & 3 & 2 \\
\hline
\end{tabular}

TABLE 4: Input parameters for training.

\begin{tabular}{lc}
\hline Input parameters for training & Values \\
\hline Error tolerance & 0.003 \\
Learning rate $(\beta)$ & 0.002 \\
Momentum parameter $(\alpha)$ & 0.002 \\
Noise factor $(\mathrm{NF})$ & 0.001 \\
Number of epochs & $1,00,00,000$ \\
Slope parameter $(\mathfrak{E})$ & 0.6 \\
Number of hidden layer neurons $(H)$ & 7 \\
Number of input layer neurons $(I)$ & 5 \\
Number of output layer neurons $(O)$ & 1 \\
\hline
\end{tabular}

generally consists of three parts connected in series: input layer, hidden layer, and output layer. The coarse information is accepted by the input layer and processed in the hidden layer. Finally the results are exported via the output layer [31]. The details of this methodology are described by Rajasekaran and Vijayalakshmi Pai [32]. Input parameters for training are given in Table 4. The three-layer neural network used in this work is shown in Figure 3. A software package NEURALNET for neural computing based on a back propagation algorithm is used as the prediction tool for erosion wear rate of the coatings under various test conditions.

\section{Results and Discussion}

3.1. Coating Thickness. The coating thickness varies appreciably with torch input power. The thickness is found to be varying in between $61 \mu \mathrm{m}$ to $220 \mu \mathrm{m}$ for mild steel substrates and $56 \mu \mathrm{m}$ to $200 \mu \mathrm{m}$ for aluminium substrates with different aluminium oxide content mixed with BGM as the power level changes gradually from $8 \mathrm{~kW}$ to $24 \mathrm{~kW}$. The gradual increase in coating thickness with increasing power level is due to better plasma-particle interaction leading to higher degree of particle melting at higher power levels.

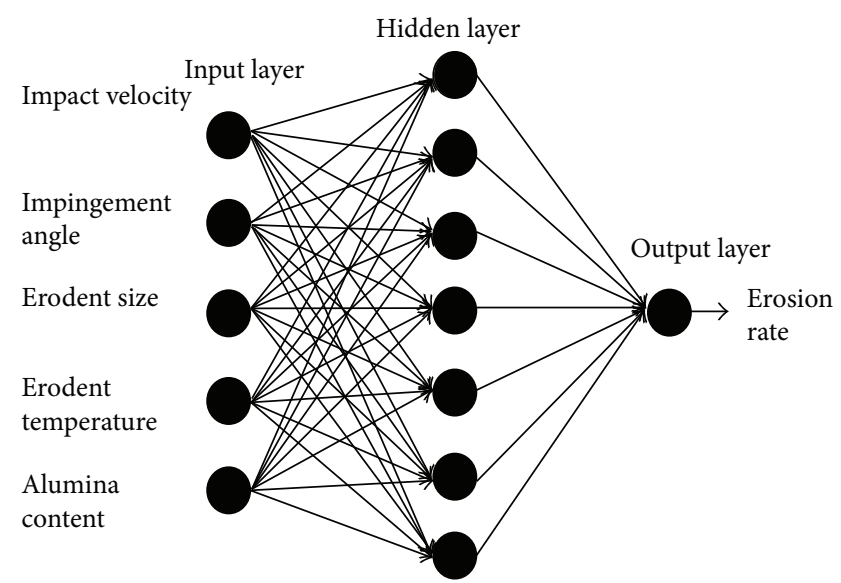

FIgURE 3: The three-layer neural network.

3.2. Coating Hardness. Microhardness measurement of the coating specimens which are metallographically polished is made using a Leitz Microhardness Tester equipped with a monitor and a microprocessor based controller. Different optically distinguishable phases bear different hardness values and the average of these values is recorded as the mean hardness of the coating. Each data point therefore is the mean of at least six or seven such readings taken on a single specimen. The values of microhardness are shown in Table 5.

3.3. Coating Adhesion Strength. To evaluate the coating adhesion strength, a horizontal table model universal testing machine PC-2000 Electronic Tenso-meter is used. The test is conducted by the pull-out method in which two cylindrical specimens are taken. The test is performed as per ASTM C633.

The variations of coating adhesion strength with torch input power level for mild steel and aluminium substrates are shown in Figures 4(a) and 4(b), respectively. Each data point on the variation curve is actually the average of values recorded in three test runs on identical specimens. From the figures, it is clear that the adhesion strength varies appreciably with operating power of the plasma torch. The strength also differs from substrate to substrate. The adhesion strength is relatively higher in case of aluminium substrate in comparison to mild steel substrate which is due to the superior thermal conductivity of aluminium.

Initially, when the operating power level is increased from $8 \mathrm{~kW}$ to $20 \mathrm{~kW}$, the melting fraction and velocity of the particles also increase. Therefore, there is better splashing and mechanical interlocking of molten particles on the substrate surface leading to an increase in adhesion strength. But, at higher power level (beyond $20 \mathrm{~kW}$ ), the amount of fragmentation and vaporization of the particles are likely to increase. There is also a greater chance of smaller particles (during in-flight traverse through the plasma) to fly off during spraying. This has resulted in poor adhesion strength of the coatings. During in-flight traverse through the plasma, BGM- $\mathrm{Al}_{2} \mathrm{O}_{3}$ particles would melt either partially or fully depending on the temperature and the flame residence time 


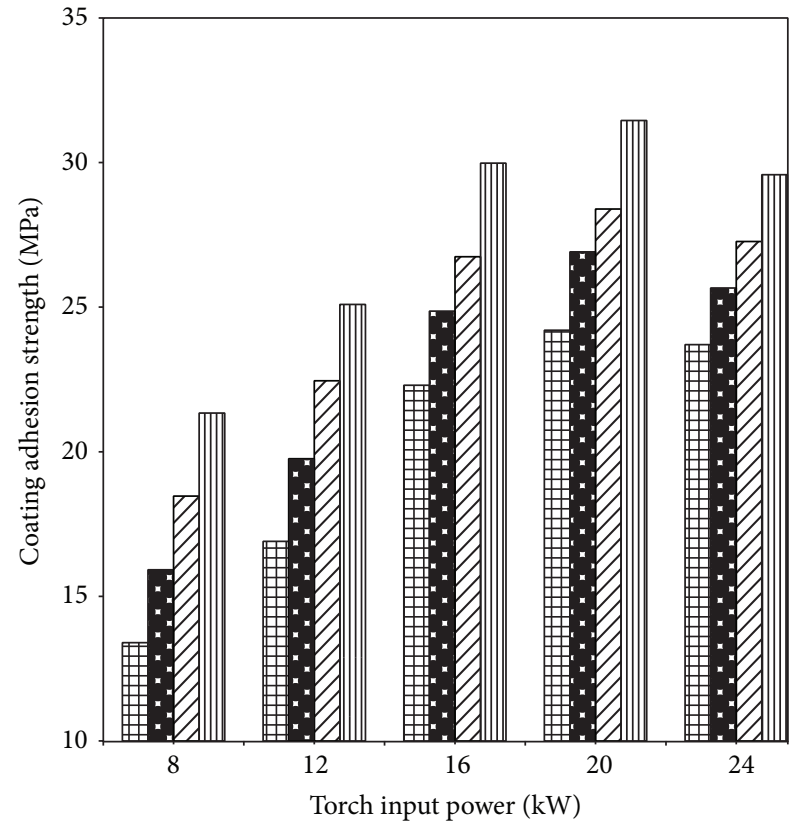

$\begin{array}{ll}\text { 四 } \mathrm{BGM} & \square \mathrm{BGM}+20 \% \mathrm{AL}_{2} \mathrm{O}_{3} \\ \text {. } \mathrm{BGM}+10 \% \mathrm{AL}_{2} \mathrm{O}_{3} & \text { 血 } \mathrm{BGM}+30 \% \mathrm{AL}_{2} \mathrm{O}_{3}\end{array}$

(a)

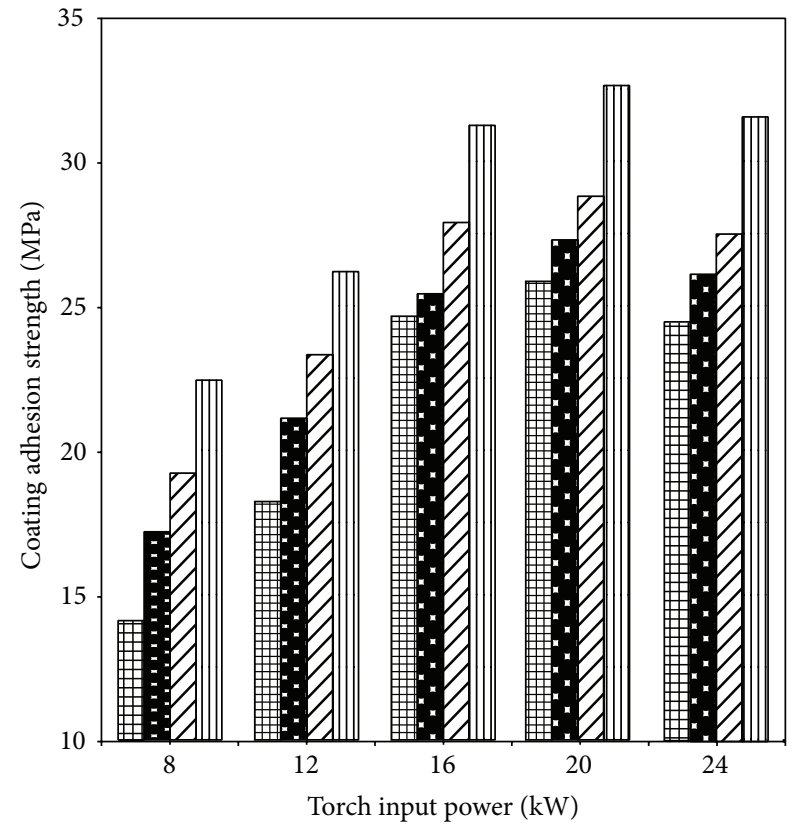

$\begin{array}{ll}\text { 目GM } & \square B G M+20 \% \mathrm{AL}_{2} \mathrm{O}_{3} \\ \mathrm{BGM}+10 \% \mathrm{AL}_{2} \mathrm{O}_{3} & \text { 血 } \mathrm{BGM}+30 \% \mathrm{AL}_{2} \mathrm{O}_{3}\end{array}$

(b)

FIGURE 4: Variation of coating adhesion strength with plasma torch input power.

TABLE 5: Variation of micro-hardness with torch input power.

\begin{tabular}{lcccc}
\hline \multirow{2}{*}{ Torch Input power $(\mathrm{kW})$} & & \multicolumn{3}{c}{ Coating Micro-hardness $(\mathrm{GPa})$} \\
& $\mathrm{BGM}$ & $\mathrm{BGM}+10 \% \mathrm{Al}_{2} \mathrm{O}_{3}$ & $\mathrm{BGM}+20 \% \mathrm{Al}_{2} \mathrm{O}_{3}$ & $\mathrm{BGM}+30 \% \mathrm{Al}_{2} \mathrm{O}_{3}$ \\
\hline 8 & 9.92 & 9.55 & 9.41 & 9.27 \\
12 & 10.12 & 9.81 & 9.74 & 9.59 \\
16 & 11.23 & 10.98 & 10.89 & 10.65 \\
20 & 11.67 & 11.41 & 11.29 & 11.13 \\
24 & 11.42 & 11.12 & 11.02 & 10.89 \\
\hline
\end{tabular}

of that particular particle. The fully molten particles take the form of spherical droplets and the partially molten ones reduce in size. Moreover, at higher operating power, due to high temperature and high enthalpy, more particles are fragmented into smaller particles. These smaller particles tend to fly off during spraying [33-35].

During the plasma particle interaction, some amount of $\mathrm{Al}$ from $\mathrm{Al}_{2} \mathrm{O}_{3}$ may be getting diffused and the presence of the diffusion layers within the splats enhances the cohesive forces between the splats which in turn establishes true metallurgical bonds between splat-splat and splat-substrate. Ageorges and Fauchais reported such an increase of adhesion strength from 50 to $80 \mathrm{MPa}$ by adding $\mathrm{Al}_{2} \mathrm{O}_{3}$ to stainless steel particles [36]. Similar observations have also been reported by previous investigators for coatings of different materials [33,37].

3.4. Scanning Electron Micrographs. SEM micrographs of uneroded and eroded surfaces for the plasma sprayed BGM$\mathrm{Al}_{2} \mathrm{O}_{3}$ coatings deposited at torch input power of $20 \mathrm{~kW}$ are shown in Figures 5(a) and 5(b) and Figures 5(c) and 5(d), respectively. Microstructures revealed are typical for a plasma spray process consisting of splats, which are of irregular shape with distinguished boundaries. A considerable amount of molten and semimolten particles are observed for the uneroded samples. The particles injected into the plasma stream get heated to temperatures much above the melting point of the materials and the molten drops are propelled through the plasma jet. The particles leave the jet fall through the atmospheric air and get quenched before they get collected in the collection chamber. The particles get spheroidized because of surface tension forces. No sizable cracks are noticed on the coating surface; however, some cavities are observed. Particle distribution seems to be uniform along the coating surface. Figures 5(c) and 5(d) show SEM micrographs of eroded surfaces of $\mathrm{BGM}-\mathrm{Al}_{2} \mathrm{O}_{3}$ coatings. As a result of repeated impact of high velocity erodent particles there is formation of grooves of different sizes. However, there is no sign of cracks seen on these micrographs. 


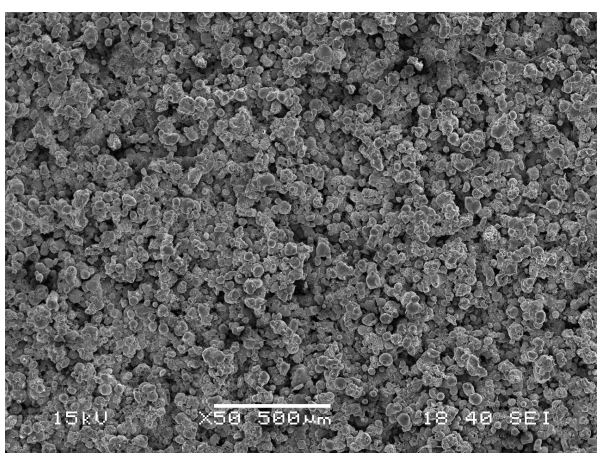

(a)

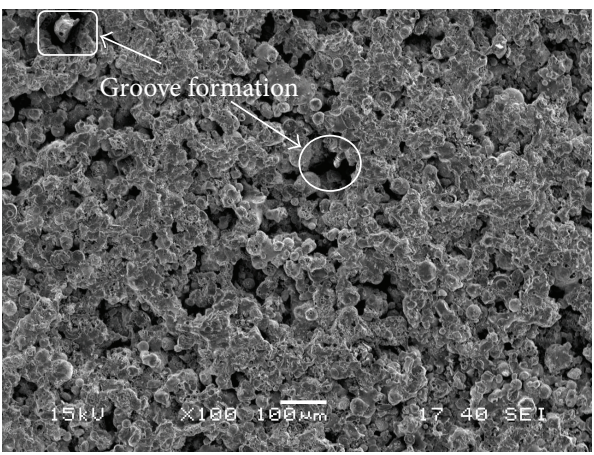

(c)

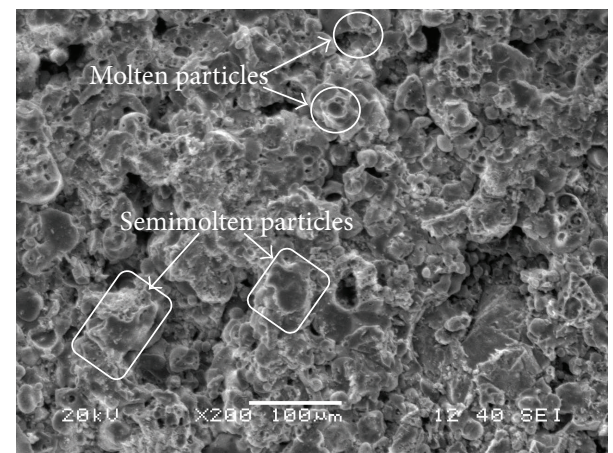

(b)

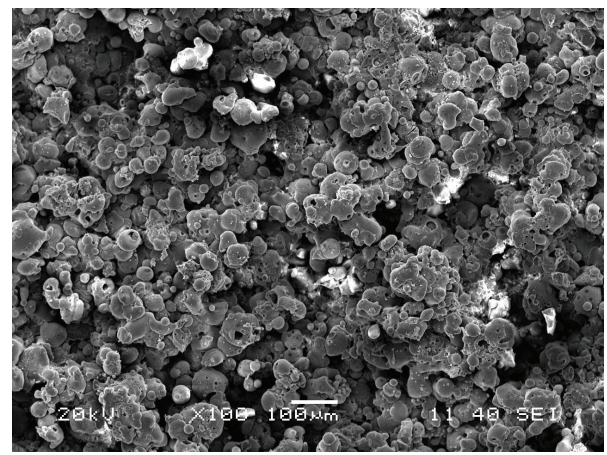

(d)

FIGURE 5: SEM micrographs of worn surfaces of the BGM coatings.

3.5. Taguchi Experimental Design. The experiments have been carried out using Taguchi experimental design $\left(\mathrm{L}_{16}\right.$ orthogonal array) given in Table 3 and the subsequent analysis of the test results is made using the popular software specifically used for design of experiment applications known as MINITAB 14.

The results of erosion experiments carried out according to the predetermined design on BGM coatings premixed with $\mathrm{Al}_{2} \mathrm{O}_{3}$ particles are presented in Table 6 . This table provides the experimental erosion rate along with the signal-to-noise ratio for each individual test run. Each value of the erosion rate is the average of three replications. The overall mean of the $S / N$ ratios is found to be $-24.3731 \mathrm{db}$. The $S / N$ ratio response analysis presented in Table 7 indicates the hierarchical order of the control factors as impact velocity $(A)$, impingement angle $(B)$, erodent size $(C)$, alumina content $(E)$, and erodent temperature $(D)$ in decreasing order according to their significance on the erosion rate. It can thus be concluded that the erodent temperature $(D)$ has negligible effect on the wear rate. The effects of control factors on erosion rate are shown in Figure 6.

Analysis of the results leads to the conclusion that factor combination of $A_{1}$ (impact velocity), $B_{1}$ (impingement angle), $C_{1}$ (erodent size), $D_{3}$ (erodent temperature), and $E_{1}$ (alumina content) gives minimum erosion rate (Figure 6 ) for coatings.

3.6. Artificial Neural Network. The ANN predictive results of erosion wear rate for all the 16 test conditions are shown and compared with the experimental values along with the associated percentage errors in Table 8 . It is observed that the errors lie in the range of $0-10 \%$, which establishes the validity of the neural computation. The errors, however, can still be reduced and the quality of predictions can be further improved by enlarging the data sets and optimizing the construction of the neural network. A well-trained ANN is expected to be very helpful for the analysis of erosion wear characteristics of any given coating and permits us to study quantitatively the effect of each of the considered input parameters on the wear rate. The range of any chosen parameter can be beyond the actual experimental limits, thus offering the possibility to use the generalization property of ANN in a large parameter space.

In the present investigation, this possibility has been explored by selecting the most significant factor; that is, the impact velocity in a range from 25 to $75 \mathrm{~m} \mathrm{~s}^{-1}$. Sets of predictions for erosion rate of coatings of different compositions at different impact velocities are evolved and this predicted evolution is illustrated in Figures 7(a) and 7(b). It is interesting to see that the erosion rate presents an exponential type evolution with the impact velocity. As the velocity of impact of the erodent increases, the kinetic energy carried by it also increases. This causes transfer of greater amount of energy to the target coating surface upon impact and leads to higher material loss due to erosion. It has also been reported by previous investigators that impact velocity happens to be an important test variable in any erosion test and can easily overshadow changes in other variables such 
Main effects plot (data means) for $S / N$ ratios

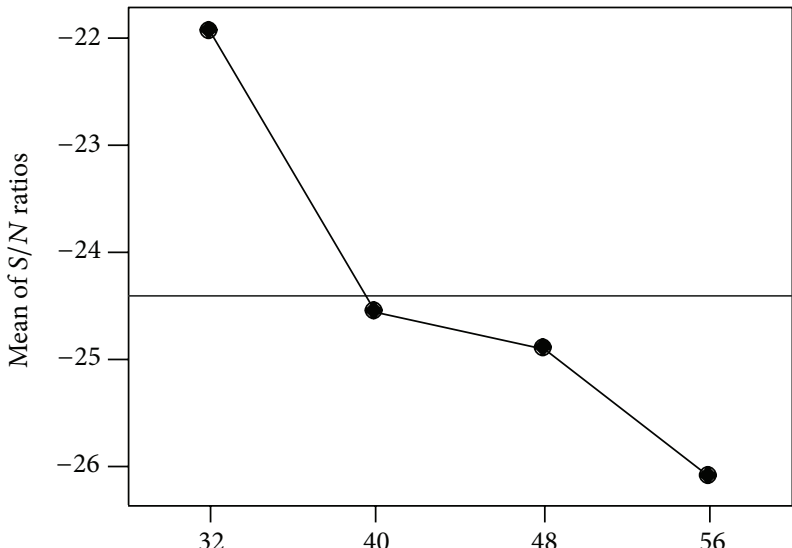

(a)

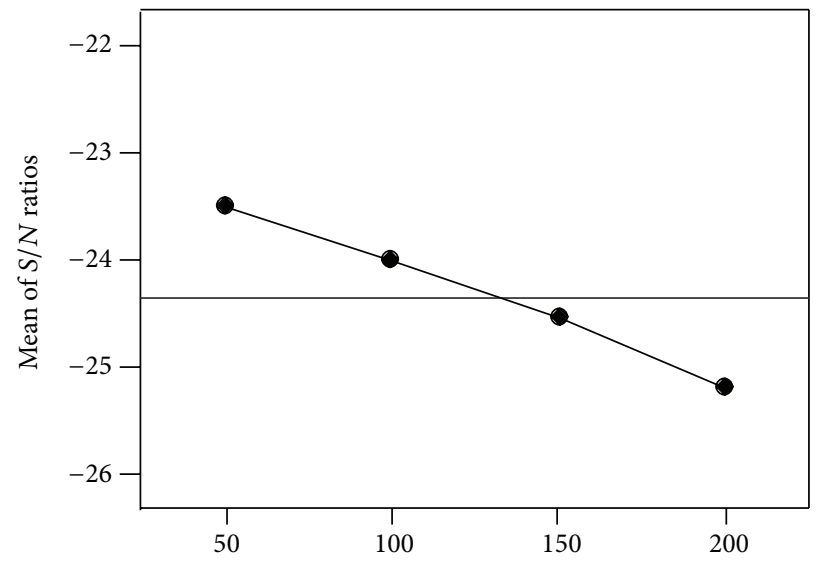

(c)

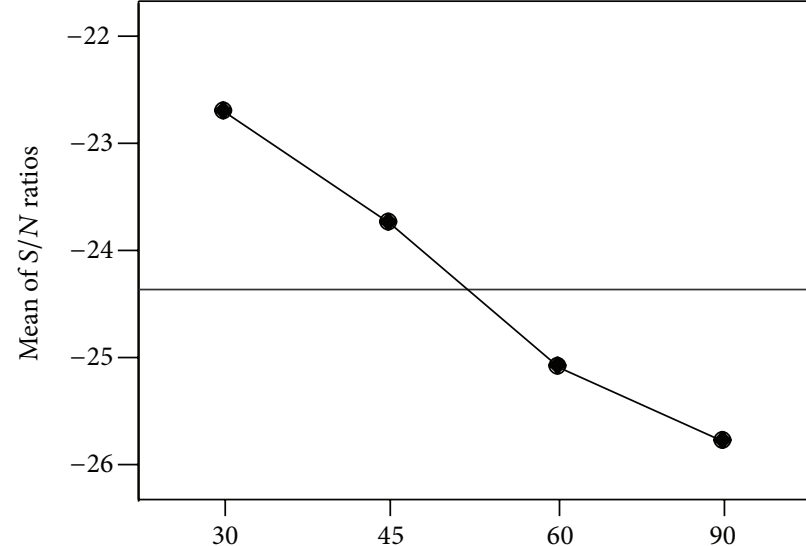

(b)

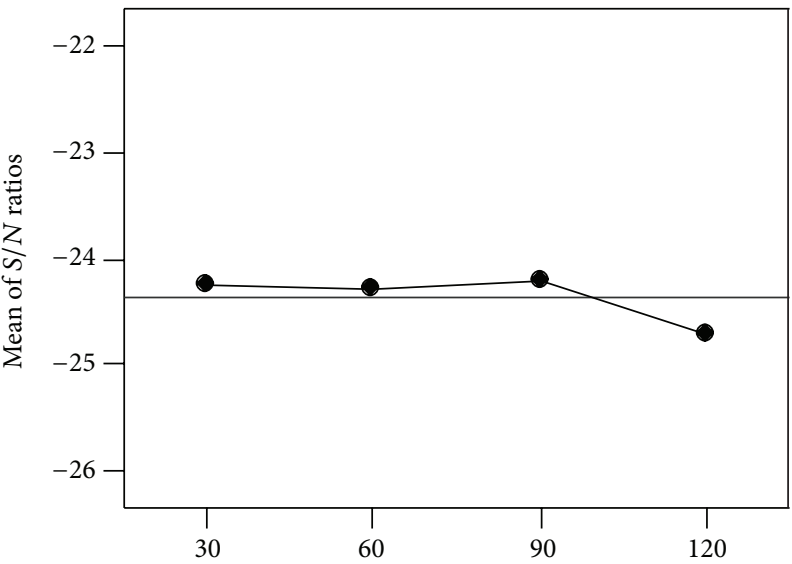

(d)

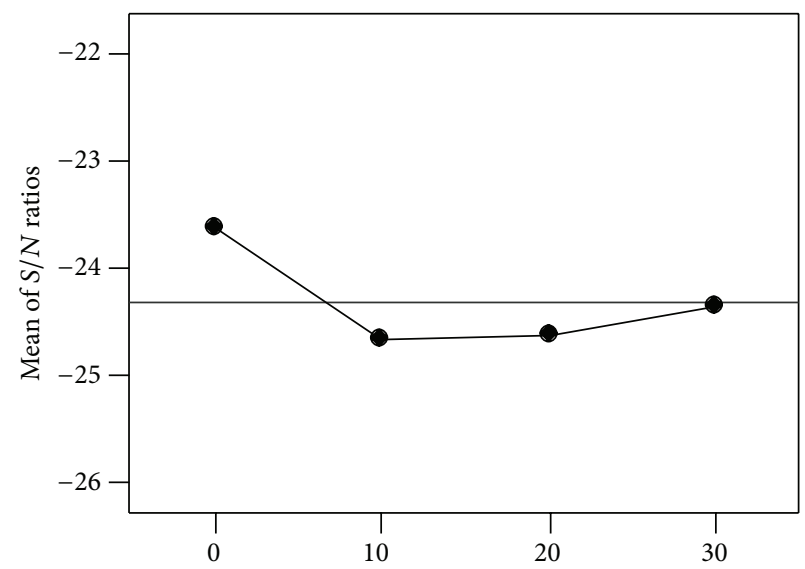

(e)

FIgURE 6: Main effect plot for $S / N$ ratio. Signal-to-noise: Smaller-is-better.

as target material and impingement angle [38]. Erosion rate (ER) depends on velocity $(V)$ by a power law, given as ER = $k V^{n}$, where $k$ is a material constant. However, the exponent $n$ is reported to be material independent and is governed by test conditions including particle characteristics and the erosion test apparatus [39-41].
3.7. Wear Prediction Using Predictive Equation. For the present investigation, an attempt has been made to find out optimal setting of control factors for minimum erosion wear rate. The single objective optimization requires quantitative determination of the relationship between erosion wear rate and control factors. In order to derive the wear rate in terms 


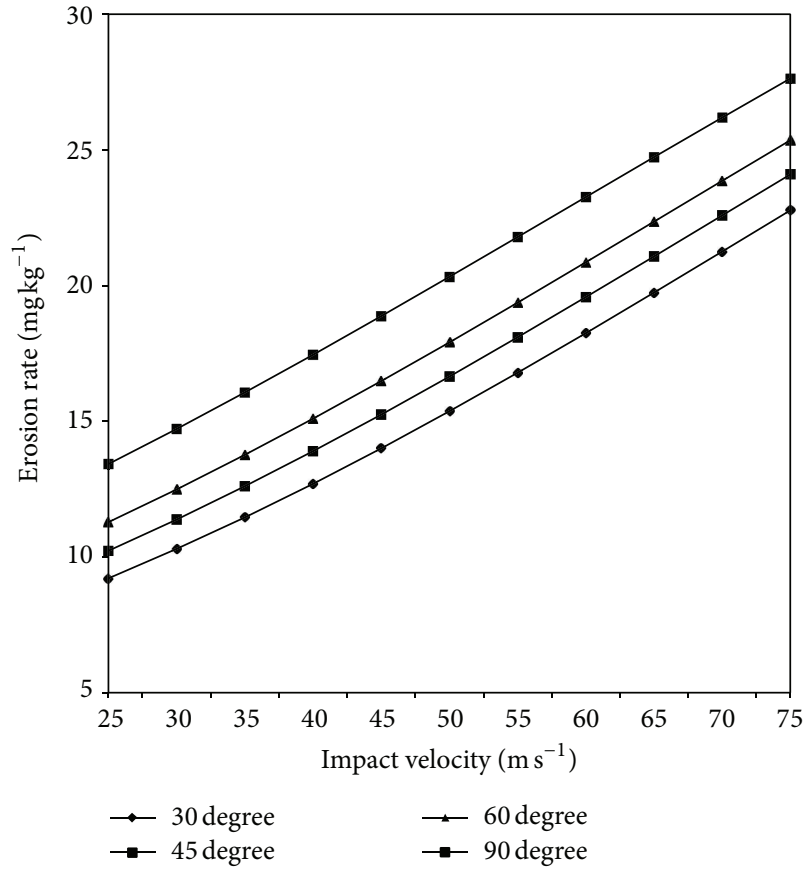

(a)

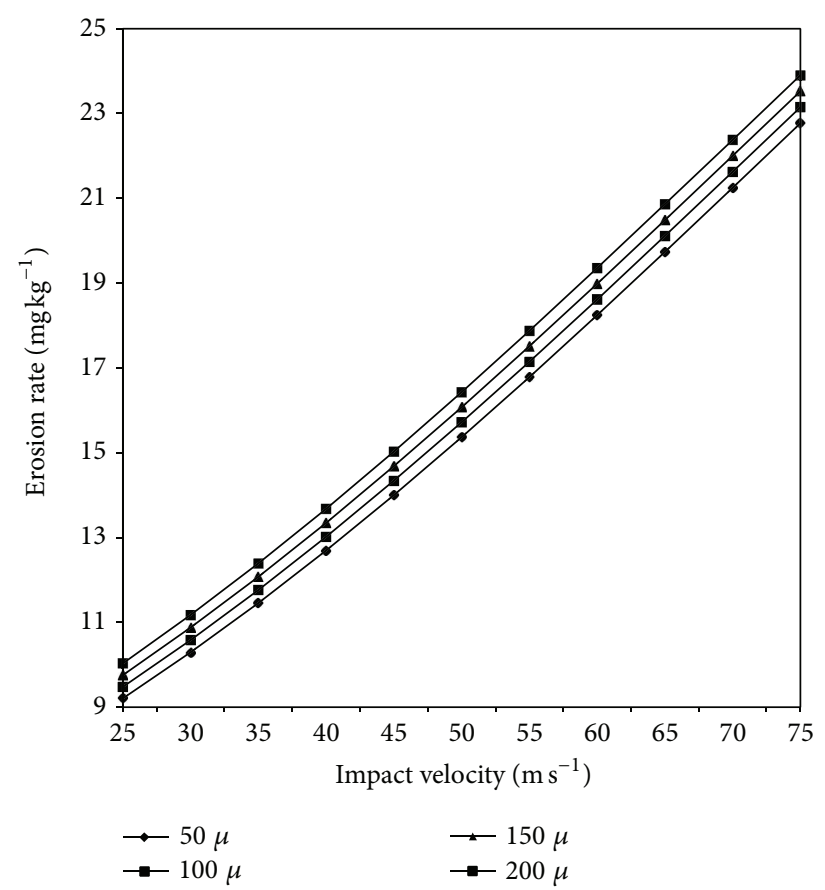

(b)

FIGURE 7: Effect of impact velocity for different (a) impingement angle and (b) erodent size.

TABLE 6: Experimental design using $\mathrm{L}_{16}$ orthogonal array and the wear test results.

\begin{tabular}{|c|c|c|c|c|c|c|}
\hline $\begin{array}{l}\text { A } \\
\text { Impact velocity } \\
\left(\mathrm{m} \mathrm{s}^{-1}\right)\end{array}$ & $\begin{array}{c}B \\
\underset{\text { Impingement angle }}{\text { (degree) }}\end{array}$ & $\begin{array}{c}C \\
\text { Erodent size }(\mu \mathrm{m})\end{array}$ & $\begin{array}{c}D \\
\text { Erodent } \\
\text { temperature } \\
\left({ }^{\circ} \mathrm{C}\right) \\
\end{array}$ & $\begin{array}{c}E \\
\text { Alumina content } \\
(\mathrm{wt} \%)\end{array}$ & $\begin{array}{l}\text { Erosion rate } \\
\left(\mathrm{mg} \mathrm{kg}^{-1}\right)\end{array}$ & $S / N$ ratio $(\mathrm{db})$ \\
\hline 32 & 30 & 50 & 30 & 0 & 8.56667 & -18.6562 \\
\hline 32 & 45 & 100 & 60 & 10 & 11.65643 & -21.3313 \\
\hline 32 & 60 & 150 & 90 & 20 & 14.23695 & -23.0683 \\
\hline 32 & 90 & 200 & 120 & 30 & 17. 04751 & -24.6332 \\
\hline 40 & 30 & 100 & 90 & 30 & 13.34126 & -22.5039 \\
\hline 40 & 45 & 50 & 120 & 20 & 15.56129 & -23.8409 \\
\hline 40 & 60 & 200 & 30 & 10 & 20.98768 & -26.4393 \\
\hline 40 & 90 & 150 & 60 & 0 & 18.81183 & -25.4886 \\
\hline 48 & 30 & 150 & 120 & 10 & 16.23178 & -24.2073 \\
\hline 48 & 45 & 200 & 90 & 0 & 16.53376 & -24.3674 \\
\hline 48 & 60 & 50 & 60 & 30 & 17.43003 & -24.8260 \\
\hline 48 & 90 & 100 & 30 & 20 & 20.46321 & -26.2195 \\
\hline 56 & 30 & 200 & 60 & 20 & 19.00984 & -25.5796 \\
\hline 56 & 45 & 150 & 30 & 30 & 19.14336 & -25.6404 \\
\hline 56 & 60 & 100 & 120 & 0 & 20.44331 & -26.2110 \\
\hline 56 & 90 & 50 & 90 & 10 & 22.27585 & -26.9567 \\
\hline
\end{tabular}

of a mathematical model, the following equation is suggested:

$$
\begin{aligned}
\mathrm{ER}= & k_{0}+k_{1} \times A+k_{2} \\
& \times B+k_{3} \times C+k_{4} \times D+k_{5} \times E .
\end{aligned}
$$

$\mathrm{ER}$ is the erosion rate in $\mathrm{mg} \mathrm{kg}^{-1}$ and $k_{i}(i=0-5)$ are the model constants. $A$ is the impact velocity $\left(\mathrm{m} \mathrm{s}^{-1}\right), B$ is the impingement angle (degree), $C$ is the erodent size $(\mu \mathrm{m}), D$ is the erodent temperature $\left({ }^{\circ} \mathrm{C}\right)$, and $E$ is the alumina content in the feedstock (wt\%). The constants are calculated using 
TABLE 7: $S / N$ ratio response table for erosion rate.

\begin{tabular}{lccccc}
\hline Level & $A$ & $B$ & $C$ & $D$ & $E$ \\
\hline 1 & -21.92 & -22.74 & -23.57 & -24.24 & -23.68 \\
2 & -24.57 & -23.80 & -24.07 & -24.31 & -24.73 \\
3 & -24.91 & -25.14 & -24.60 & -24.22 & -24.68 \\
4 & -26.10 & -25.82 & -25.25 & -24.72 & -24.40 \\
Delta & 4.17 & 3.09 & 1.68 & 0.50 & 1.05 \\
Rank & $\mathbf{1}$ & $\mathbf{2}$ & $\mathbf{3}$ & $\mathbf{5}$ & $\mathbf{4}$ \\
\hline
\end{tabular}

TABLE 8: Percentage error between experimental result and ANN prediction.

\begin{tabular}{lccc}
\hline \multirow{2}{*}{ Test run } & \multicolumn{3}{c}{ Erosion rate $\left(\mathrm{mg} \mathrm{kg}^{-1}\right)$} \\
& Experimental result & ANN prediction & Error (\%) \\
\hline 1 & 8.56667 & 9.0548 & 5.698013 \\
2 & 11.65643 & 11.7859 & 1.110717 \\
3 & 14.23695 & 13.254 & 6.90422 \\
4 & 17.04751 & 18.4587 & 8.277983 \\
5 & 13.34126 & 13.3369 & 0.03268 \\
6 & 15.56129 & 14.589 & 6.24813 \\
7 & 20.98768 & 21.4589 & 2.245222 \\
8 & 18.81183 & 18.1495 & 3.52082 \\
9 & 16.23178 & 15.5895 & 3.95693 \\
10 & 16.53376 & 16.4859 & 0.28947 \\
11 & 17.43003 & 17.2458 & 1.05697 \\
12 & 20.46321 & 21.5487 & 5.304593 \\
13 & 19.00984 & 18.865 & 0.76192 \\
14 & 19.14336 & 20.0014 & 4.482181 \\
15 & 20.44331 & 20.221 & 1.08745 \\
16 & 22.27585 & 24.3568 & 9.341731 \\
\hline
\end{tabular}

nonlinear regression analysis with the help of SYSTAT 7 software and the following relation is obtained:

$$
\begin{aligned}
\mathrm{ER}= & -2.72+0.282 \times A+0.091 \\
& \times B+0.016 \times C+0 \times D+0.014 \times E .
\end{aligned}
$$

The correctness of the calculated constants is confirmed as high correlation coefficient $\left(r^{2}\right)$ to the tune of 0.995 is obtained for erosion wear rate and therefore the model is quite suitable to be used for predictive purpose. A comparison of erosion rate of the coatings with the experimental values is presented in Table 9 which indicates that the percentage error associated with the predicted values with respect to the experimental one varies in the range of 0 to $12 \%$.

\section{Conclusions}

Borosilicate glass microspheres premixed with $\mathrm{Al}_{2} \mathrm{O}_{3}$ can be used as a potential material for producing wear resistant coatings. Samples coated with $\mathrm{BGM}-\mathrm{Al}_{2} \mathrm{O}_{3}$ exhibit properties like good adhesion strength and hardness desirable for tribological applications. Erosion wear characteristics of these coating can be analyzed following a design of experiment approach. This study reveals that among all the control factors, impact
TABLE 9: Comparison between experimental and predicted values

\begin{tabular}{|c|c|c|}
\hline \multicolumn{2}{|c|}{ Erosion rate $\left(\mathrm{mg} \mathrm{kg}^{-1}\right)$} & \multirow[b]{2}{*}{$\begin{array}{l}\text { Percentage } \\
\text { error }\end{array}$} \\
\hline $\begin{array}{l}\text { Obtained from } \\
\text { experimentation }\end{array}$ & $\begin{array}{c}\text { Obtained from } \\
\text { predictive equation }\end{array}$ & \\
\hline 8.56667 & 9.487 & 10.743 \\
\hline 11.65643 & 12.139 & 4.140 \\
\hline 14.23695 & 14.444 & 1.454 \\
\hline 17. 04751 & 18.114 & 6.256 \\
\hline 13.34126 & 13.31 & 0.234 \\
\hline 15.56129 & 13.735 & 11.736 \\
\hline 20.98768 & 19.56 & 6.802 \\
\hline 18.81183 & 19.15 & 1.798 \\
\hline 16.23178 & 16.086 & 0.898 \\
\hline 16.53376 & 18.111 & 9.540 \\
\hline 17.43003 & 17.496 & 0.379 \\
\hline 20.46321 & 20.886 & 2.066 \\
\hline 19.00984 & 19.282 & 1.432 \\
\hline 19.14336 & 19.987 & 4.407 \\
\hline 20.44331 & 20.132 & 1.523 \\
\hline 22.27585 & 22.202 & 0.332 \\
\hline
\end{tabular}
for erosion rat.

velocity is the most significant factor affecting the wear rate of these coatings. Premixing of $\mathrm{Al}_{2} \mathrm{O}_{3}$ with glass microspheres improves the coating adhesion strength without significantly affecting the erosion wear performance of the coatings. ANN technique is successfully applied in this investigation and it is seen that the use of the neural network model to simulate experiments with parametric design strategy is quite effective for prediction of wear response of such coatings within and beyond the experimental domain.

\section{Conflict of Interests}

The authors declare that there is no conflict of interests regarding the publication of this paper.

\section{References}

[1] S. C. Mishra, S. Das, A. Satapathy, S. Sarkar, P. V. Ananthapadmanabhan, and K. P. Sreekumar, "Investigation on composite coating of low grade minerals," Journal of Reinforced Plastics and Composites, vol. 28, no. 24, pp. 3061-3067, 2009.

[2] F. Kassabji, J. P. Durand, and G. Jacq, "Thermal spray application for the next millennium a business development perspective," in Proceedings of the International Thermal Spray Conference: Thermal Spray Meeting the Challenges of the 21st Century, pp. 1677-1680, Cincinnati, Ohio, USA, May 1998.

[3] W. Hangong and W. Liuying, "Thermal spray connects: explore its surface potential," in Proceedings of the International Thermal Spray Conference (ITSC '05), E. Lugscheider, Ed., p. 29, ASM International, Basel, Switzerland, 2005.

[4] J. M. Guilemany, J. Nin, and J. R. Miguel, "Thermal spray connects: explore its surface potential," in Proceedings of the International Thermal Spray Conference (ITSC '05), E. Lugscheider, Ed., p. 36, ASM International, Basel, Switzerland, 2005. 
[5] T. Mckechnie, "Near-net shape spray forming-metals," in Thermal Spray: Surface Engineering Through Applied Research, C. C. Berndt, Ed., pp. 1105-1116, ASM International, Materials Park, Ohio, USA, 2000.

[6] T. Mckechnie, "Hard chrome replacement and other thermal spray application in the Chilean Navy," in Thermal Spray: Surface Engineering Through Applied Research, C. C. Berndt, Ed., pp. 1145-1148, ASM International, Materials Park, Ohio, USA, 2000.

[7] W. Mallèner, W. Hohenauer, and D. Stover, "Tungsten coatings for nuclear-fusion devices," in Thermal Spray: Practical Solutions Goes Engineering Problems, C. C. Berndt, Ed., pp. 1-6, ASM International, Materials Park, Ohio, USA, 1996.

[8] Y. Wang, K. A. Khor, and P. Cheang, "Thermal spraying of functionally graded calcium phosphate coatings for biomedical implants," Journal of Thermal Spray Technology, vol. 7, no. 1, pp. 50-57, 1998.

[9] C. R. C. Lima and J. M. Guilemany, "Adhesion improvements of Thermal Barrier Coatings with HVOF thermally sprayed bond coats," Surface and Coatings Technology, vol. 201, no. 8, pp. 4694-4701, 2007

[10] A. R. M. Sahab, N. H. Saad, S. Kasolang, and J. Saedon, "Impact of plasma spray variables parameters on mechanical and wear behaviour of plasma sprayed $\mathrm{Al}_{2} \mathrm{O}_{3} 3 \%$ wt $\mathrm{TiO}_{2}$ coating in abrasion and erosion application," Procedia Engineering, vol. 41, pp. 1689-1695, 2012.

[11] S. B. Mishra, S. Prakash, and K. Chandra, "Studies on erosion behaviour of plasma sprayed coatings on a Ni-based superalloy," Wear, vol. 260, no. 4-5, pp. 422-432, 2006.

[12] S. J. Matthews, B. J. James, and M. M. Hyland, "Microstructural influence on erosion behaviour of thermal spray coatings," Materials Characterization, vol. 58, no. 1, pp. 59-64, 2007.

[13] V. P. Singh, A. Sil, and R. Jayaganthan, "A study on sliding and erosive wear behaviour of atmospheric plasma sprayed conventional and nanostructured alumina coatings," Materials and Design, vol. 32, no. 2, pp. 584-591, 2011.

[14] M. Mohanty, R. W. Smith, M. De Bonte, J. P. Celis, and E. Lugscheider, "Sliding wear behavior of thermally sprayed 75/25 $\mathrm{Cr}_{3} \mathrm{C}_{2} / \mathrm{NiCr}$ wear resistant coatings," Wear, vol. 198, no. 1-2, pp. 251-266, 1996.

[15] S. P. Sahu, A. Satapathy, A. Patnaik, K. P. Sreekumar, and P. V. Ananthapadmanabhan, "Development, characterization and erosion wear response of plasma sprayed fly ash-aluminum coatings," Materials and Design, vol. 31, no. 3, pp. 1165-1173, 2010.

[16] S. K. Acharya, V. Dikshit, and P. Mishra, "Erosive wear behaviour of redmud filled metal matrix composite," Journal of Reinforced Plastics and Composites, vol. 27, no. 2, pp. 145-152, 2008.

[17] S. C. Mishra, S. Das, A. Satapathy, P. V. Ananthapadmanabhan, and K. P. Sreekumar, "Erosion wear analysis of plasma sprayed ceramic coating using the taguchi technique," Tribology Transactions, vol. 52, no. 3, pp. 401-404, 2009.

[18] S. P. R. Sahu, A. Satapathy, D. Mishra, A. Patnaik, and K. P. Sreekumar, "Tribo-performance analysis of fly ash-aluminum coatings using experimental design and ANN," Tribology Transactions, vol. 53, no. 4, pp. 533-542, 2010.

[19] T. H. Kosel, "Solid particle erosion," in ASM Handbook, vol. 18 of Friction, Lubrication, and Wear Technology, pp. 199-213, American Society for Metals, 1992.

[20] Y. Zhang, Y.-B. Cheng, and S. Lathabai, "Erosion of alumina ceramics by air- and water-suspended garnet particles," Wear, vol. 240 , no. 1-2, pp. 40-51, 2000.
[21] R. J. K. Wood, "The sand erosion performance of coatings," Materials and Design, vol. 20, no. 4, pp. 179-191, 1999.

[22] ASM, ASM Handbook: Friction, Lubrication, and Wear Technology, vol. 18, ASM International, 1992.

[23] Y. Sahin, "The prediction of wear resistance model for the metal matrix composites," Wear, vol. 258, no. 11-12, pp. 1717-1722, 2005.

[24] G. Gupta and A. Satapathy, "Modified mechanical and wear characteristics of epoxy filled with borosilicate glass microspheres," in Proceedings of the International Conference on Advancements in Polymeric Materials, CIPET, Lucknow, India, 2013.

[25] S. P. Sahu, A. Satapathy, A. Patnaik, K. P. Sreekumar, and P. V. Ananthapadmanabhan, "Development, characterization and erosion wear response of plasma sprayed fly ash-aluminum coatings," Materials and Design, vol. 31, no. 3, pp. 1165-1173, 2010.

[26] V. Singh, V. Tathavadkar, S. M. Rao, and K. S. Raju, "Predicting the performance of submerged arc furnace with varied raw material combinations using artificial neural network," Journal of Materials Processing Technology, vol. 183, no. 1, pp. 111-116, 2007.

[27] A. Bezazi, S. G. Pierce, K. Worden, and E. H. Harkati, "Fatigue life prediction of sandwich composite materials under flexural tests using a Bayesian trained artificial neural network," International Journal of Fatigue, vol. 29, no. 4, pp. 738-747, 2007.

[28] M. S. Al-Haik, M. Y. Hussaini, and H. Garmestani, "Prediction of nonlinear viscoelastic behavior of polymeric composites using an artificial neural network," International Journal of Plasticity, vol. 22, no. 7, pp. 1367-1392, 2006.

[29] G. Gupta, S. K. Mishra, S. Mantry, and A. Satapathy, "Preparation and characterization of thermal spray coating of glass micro-spheres on metal substrate," Advanced Materials Research, vol. 585, pp. 502-506, 2012.

[30] H. A. Aglan and T. A. Chenock Jr., "Erosion damage features of polyimide thermoset composites," Sampe Quarterly, vol. 24, no. 2, pp. 41-47, 1993.

[31] S. Haykin, Neural Networks: A Comprehensive Foundation, Prentice Hall, Upper Saddle River, NJ, USA, 1999.

[32] S. Rajasekaran and G. A. Vijayalakshmi Pai, Neural Networks, Fuzzy Logic and Genetic Algorithms-Synthesis and Applications, Prentice Hall, New Delhi, India, 2003.

[33] A. Satapathy, Thermal spray coating of red mud on metals [Ph.D. thesis], NIT, Rourkela, India, 2006.

[34] A. Satapathy, S. C. Mishra, P. V. Ananthapadmanabhan, and K. P. Sreekumar, "Development of ceramic coatings using red mud-a solid waste of alumina plants," Journal of Solid Waste Technology and Management, vol. 33, no. 2, pp. 108-113, 2007.

[35] A. Satapathy, S. P. Sahu, and D. Mishra, "Development of protective coatings using fly ash premixed with metal powder on Aluminium substrates," Waste Management and Research, vol. 28, no. 7, pp. 660-666, 2010.

[36] H. Ageorges and P. Fauchais, "Plasma spraying of stainless-steel particles coated with an alumina shell," Thin Solid Films, vol. 370, no. 1, pp. 213-222, 2000.

[37] M. Ahmaruzzaman, "A review on the utilization of fly ash," Progress in Energy and Combustion Science, vol. 36, no. 3, pp. 327363, 2010.

[38] B. A. Lindsley and A. R. Marder, "The effect of velocity on the solid particle erosion rate of alloys," Wear, vol. 225-229, pp. 510516, 1999. 
[39] Q. Chen and D. Y. Li, "Computer simulation of solid particle erosion," Wear, vol. 254, no. 3-4, pp. 203-210, 2003.

[40] J. John Rajesh, J. Bijwe, B. Venkataraman, and U. S. Tewari, "Effect of impinging velocity on the erosive wear behaviour of polyamides," Tribology International, vol. 37, no. 3, pp. 219-226, 2004.

[41] D. López, J. P. Congote, J. R. Cano, A. Toro, and A. P. Tschiptschin, "Effect of particle velocity and impact angle on the corrosion-erosion of AISI 304 and AISI 420 stainless steels," Wear, vol. 259, no. 1-6, pp. 118-124, 2005. 

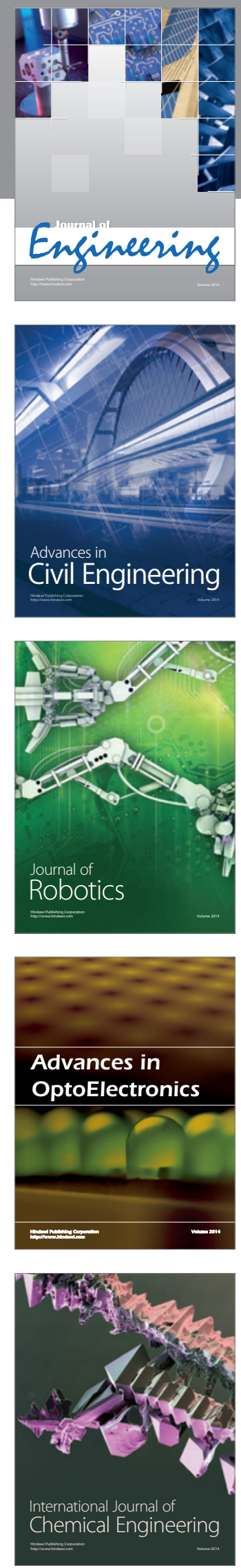

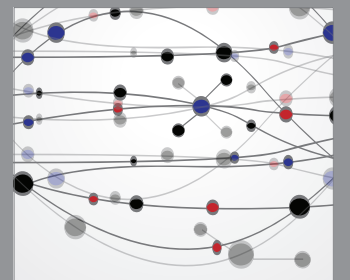

The Scientific World Journal
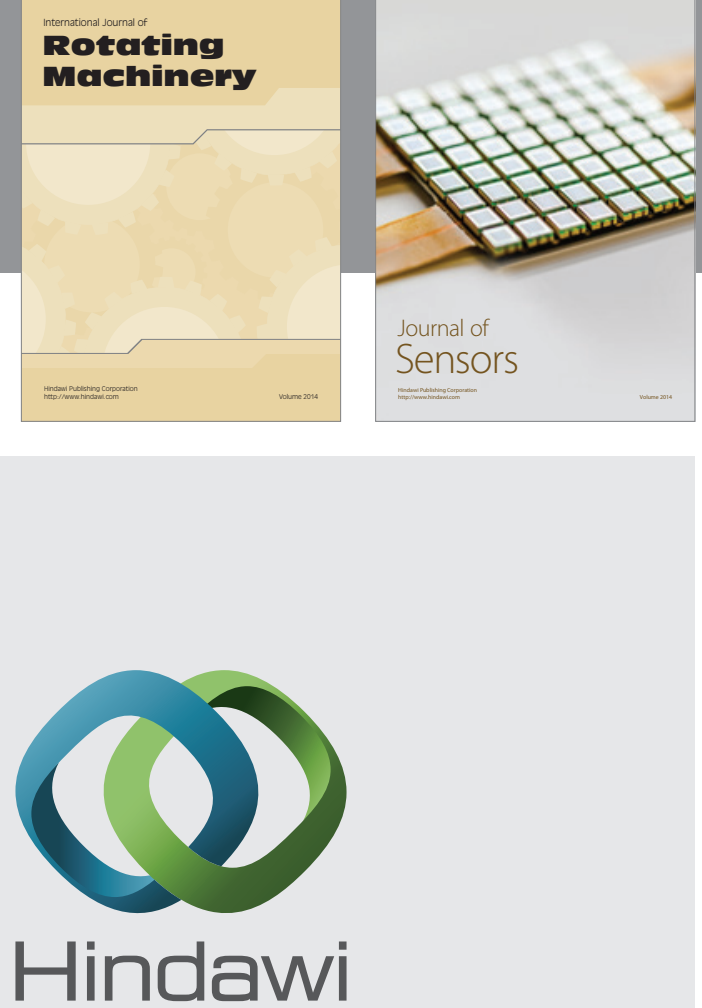

Submit your manuscripts at http://www.hindawi.com
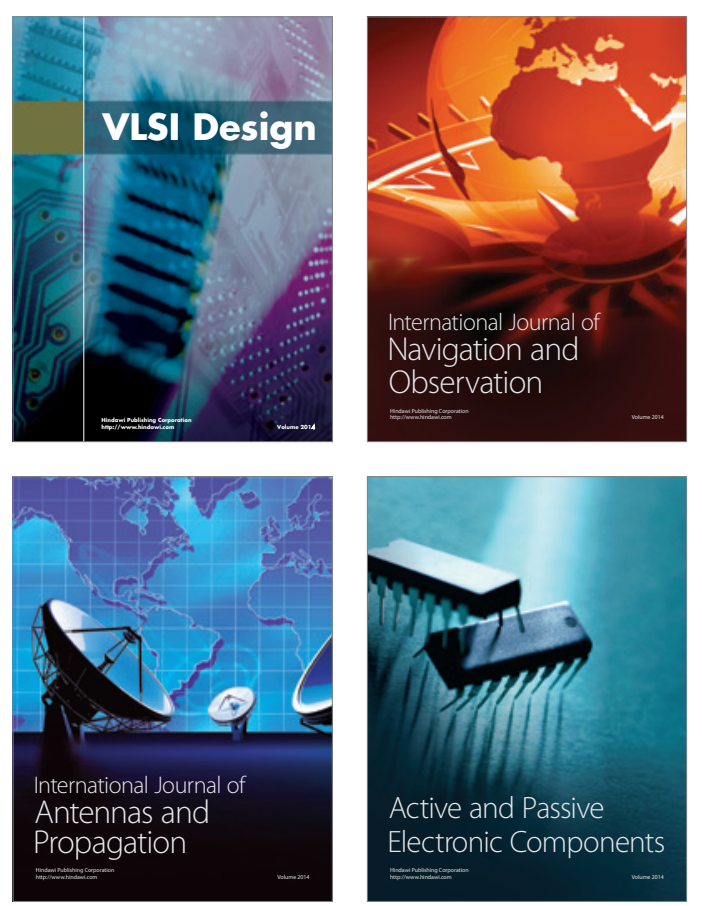
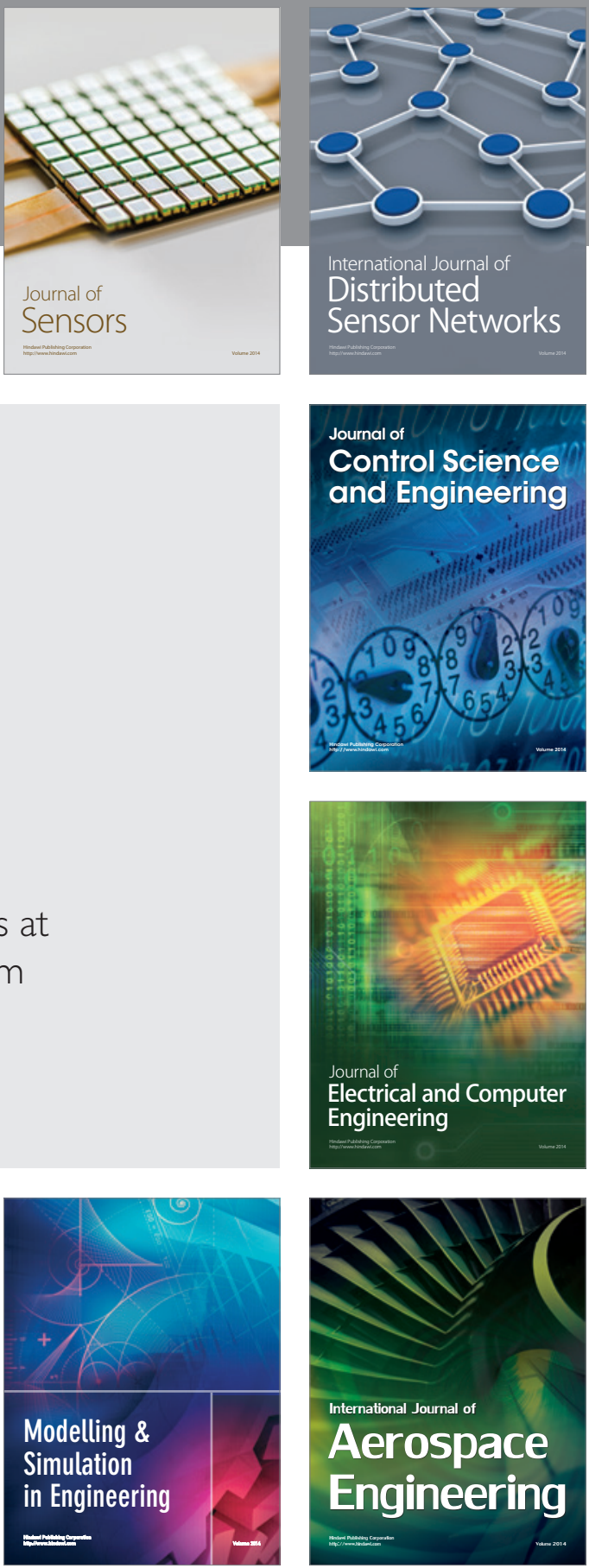

Journal of

Control Science

and Engineering
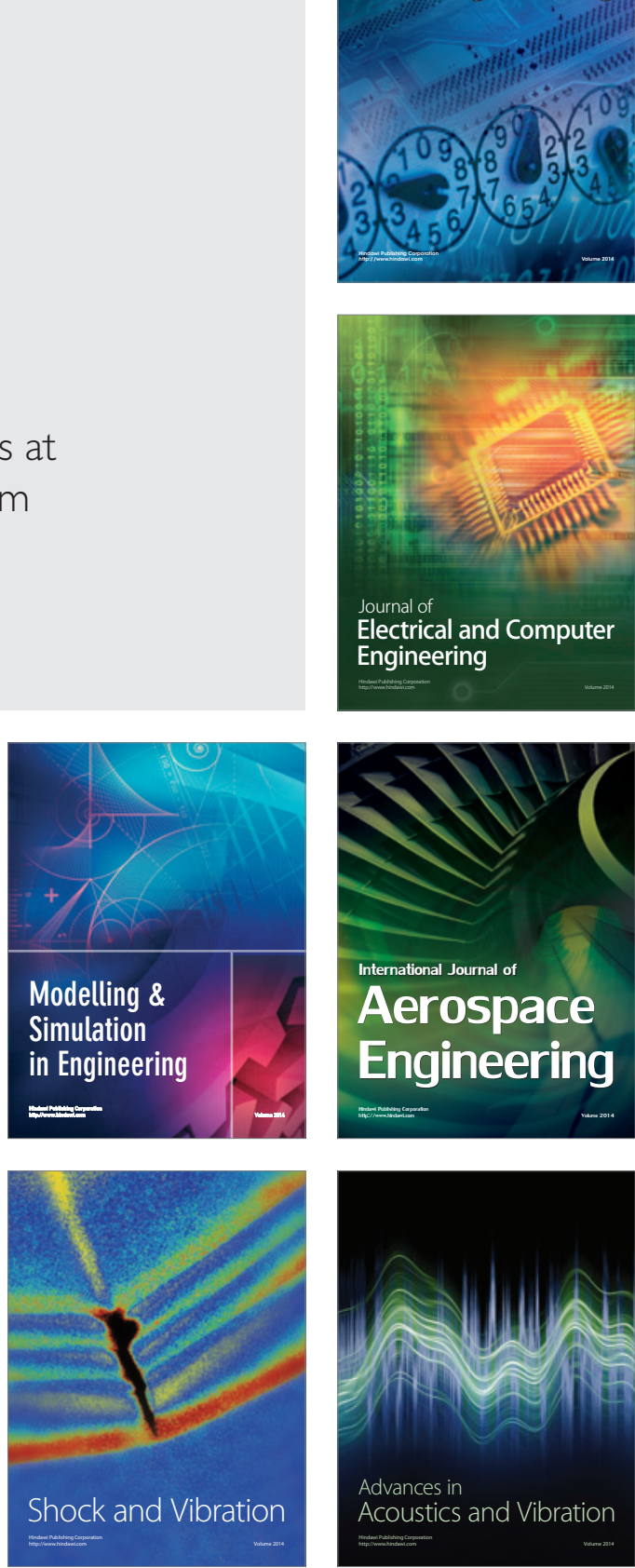